\title{
Comparing the Accuracy of Network Utilization Performance between Real Network and Simulation Model for Local Area Network (LAN)
}

\author{
Mohd Nazri ISMAIL ${ }^{1}$, Abdullah Mohd ZIN ${ }^{2}$ \\ ${ }^{I}$ Faculty of MIIT, University Kuala Lumpur, Malaysia \\ ${ }^{2}$ Faculty of Computer Science, UKM, Malaysia \\ Email:mnazrii@miit.unikl.edu.my \\ Received March 6, 2008; revised August 22, 2008; accepted October 8, 2008
}

\begin{abstract}
This article presents a novel approach for the measurement and estimation of network traffic utilization between network nodes in heterogeneous environment. This research investigates performance evaluation of network interface on heterogeneous services and technologies environment. This study proposes an enhanced equation to evaluate the performance of network interface via Little Law and Queuing theories to improve the evaluation algorithm. To get accuracy results on the performance of simulation model, it measures (verify and validate) data from Local Area Network (real network environment). This project uses network management tool to capture those data and Fluke Optiview device to generate traffic. As a result, this simulation model can provide a good approximation of the real traffic observed in the real network environment. Through laboratory and field experiments, the result shows that the model via simulation is capable of approximating the performance of network utilization and traffic over heterogeneous services and techniques within a minimum error range.
\end{abstract}

Keywords: Network Utilization, Real Network, LAN

\section{Introduction}

Considerable research has been conducted to model and quantify the performance of heterogeneous services and technologies (e.g., [1-3]). Accurate measurements and analyses of network characteristics are essential for robust network performance and management. However, no current research specifically focuses on using queuing theory to measure heterogeneous services and technologies performance, which is the object of this research. Queuing theory [4] has been used as an effective tool to model performance in several technical and social contexts. Evaluating the performance of a computer networking usually involves constructing an appropriate model to predict the heterogeneous environment behaviour via simulation model. The heterogeneous environment model is then analyzed and simulated using mathematical techniques. For example, several flowlevel network traffic models have been proposed to describe/stimulate [5-7]. These models have been used to study fairness, response times, queue lengths and loss probabilities under different assumptions and using a variety of mathematical techniques. Queuing theory has been widely used to model and analyze the network performance of complex systems involving services, communication systems, computer networks and vehicular traffic. In contrast to other works in the literature (e.g., [8-10]), developed simulation model to measure the performance of heterogeneous environment. Our model can be used to generate representative packet traffic in a live network environment or in a simulated environment.

The significant of this study was to develop a simulation model to measure the performance of network traffic utilization in heterogeneous network environment using Queuing theory. This model could assist network administrators to design and manage heterogeneous network systems. This simulation model can be used in various services and technologies to measure heterogeneous environment. Therefore, this simulation model is designed 
to: 1) predict the performance of various services (e.g. video, audio, voice and message) in order to aid technology assessment and capacity planning; 2) predict the expected behavior of new services and designs through qualitative or quantitative estimates of network performance; 3) assist network administrator to prepare, propose, plan and design network topology more effective and systematic; and 4) conduct "What-If" analysis for evaluating heterogeneous network environment performance. Moreover, in the future, the integration of data and communication services, almost every "Internet Ready" device will be a communicable device [11]. With the availability of this infrastructure, users are now demanding and expecting more services $[12,13]$. Convergence is pushing towards an environment that requires new investment in infrastructure and able to support the delivery of rich services (various services), applications and content [5,14]. In addition, more people are using multimedia services such as MMS, WAP, imode or push-to-talk. GPRS (General Packet Radio Service) is an overlay on GSM networks that allows this kind of end-to-end IP-based packet traffic from mobile devices to the Internet [15]. Network deployment is growing increasing complex as the industry lashes together a mix of wired and wireless technologies into large-scale heterogeneous network architecture and as user applications and traffic continue to evolve. Faced with this growing complexity, network designers and researchers almost universally use simulation in order to predict the expected performance of complex networks [16]. The successful evolution of the Internet is tightly coupled to the ability to design simple and accurate models [17]. Many factors may contribute to the congestion of network interface, such as a heavy load in the network that usually generates higher traffic. Once the number of requests exceeds the maximum capability of network, many clients will not able to receive responses from the network [18]. Thus, this research is critical to be conducted in order to predict and measure of network traffic utilization in heterogeneous environment.

\section{Problem Statements}

In the 21 century, a network infrastructure is based on multi-service implementation over convergence of network medium such as ISP, PSTN and GSM [19,20]. Availability of various services has produced multitraffic in network infrastructure. Therefore, multi-traffic in the network infrastructure has become more complex to observe and analyze [14,21,22]. Today, retrieving and sending information can be done using a variety of technologies such as PC, PDA, fix and mobile phones via the wireless, high speed network, ISDN and ADSL lines that are more prone to heterogeneous environment, but unfortunately the optimal capability of technologies are not fully realized. The main factors of network congestion are related to network design and bandwidth capacity [23]. Nevertheless, few studies have been conducted to evaluate the application of computer network technologies and services over heterogeneous environment especially in Higher Education Institutes. Algorithms for actively measuring network physical and available bandwidths have been researched for many years. Many tools have been developed, and only a few tools have successfully achieved a close estimation of network bandwidths [3]. Therefore, retrieving and sending information over heterogeneous environment using convergence of technologies in Higher Educational Institutes should be analyzed and evaluated via simulation model. This research has setup a pilot test-bed (real network environment) to analyze and measure of network traffic utilization at University of Kuala Lumpur in Malaysia. This study posits several research questions: 1) what is the performance level of the network utilization and traffic; and 2) Is the simulation model for evaluating and measuring the heterogeneous environment performance effective?

\section{Methodologies}

Whatever modeling paradigm or solution techniques in heterogeneous environment model development are being used, the performance measures extracted from a simulation model must be a good representation of the real network environment. Inevitably, some assumptions must be made about the real network in order to construct the heterogeneous environment model. Figure 1 shows the overall framework of the simulation model. There are four performance techniques to validate the simulation model: 1) graphical representation; 2) tracing; 3) parameter variability; and 4) predictive validation. In addition, there are two techniques to judging how good a model is with respect to the real network: 1) it must ascertain whether the simulation model implements the assumptions correctly (model verification); and 2) assumptions which have been made are reasonable with respect to the real network (model validation). Comparison with a real network is the most reliable and preferred method to validate a simulation model (refer to Figure 2). Assumptions, input values, output values, workloads, configurations and network system behaviour should all be compared with those observed in the real network.

\section{Propose Simulation Model Development for Network Utilization and Traffic}

Many different types of modeling and simulation applications are used in various disciplines such as acquisition, analysis, education, entertainment, research and training [24]. In the Figure 3, theoretical model is based on a random distribution of service duration. "Request" defines the way clients use the computer network to request services, while, "Response" represents the way 


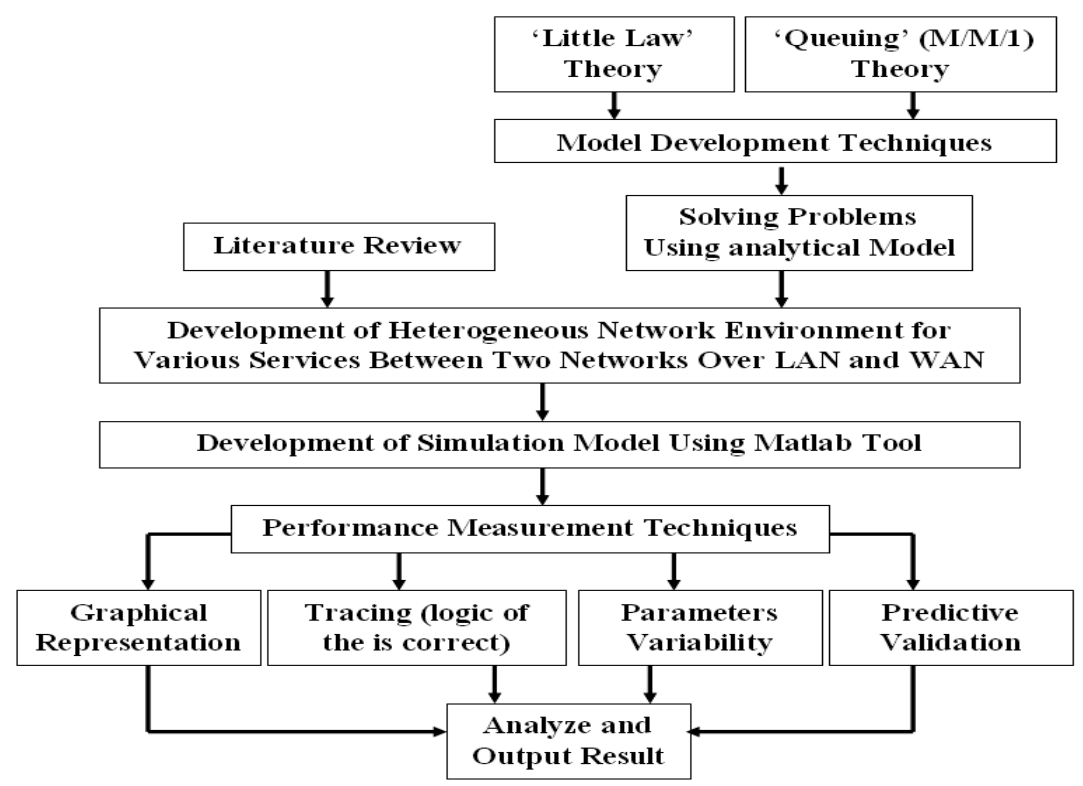

Figure 1. Simulation model development methodology.

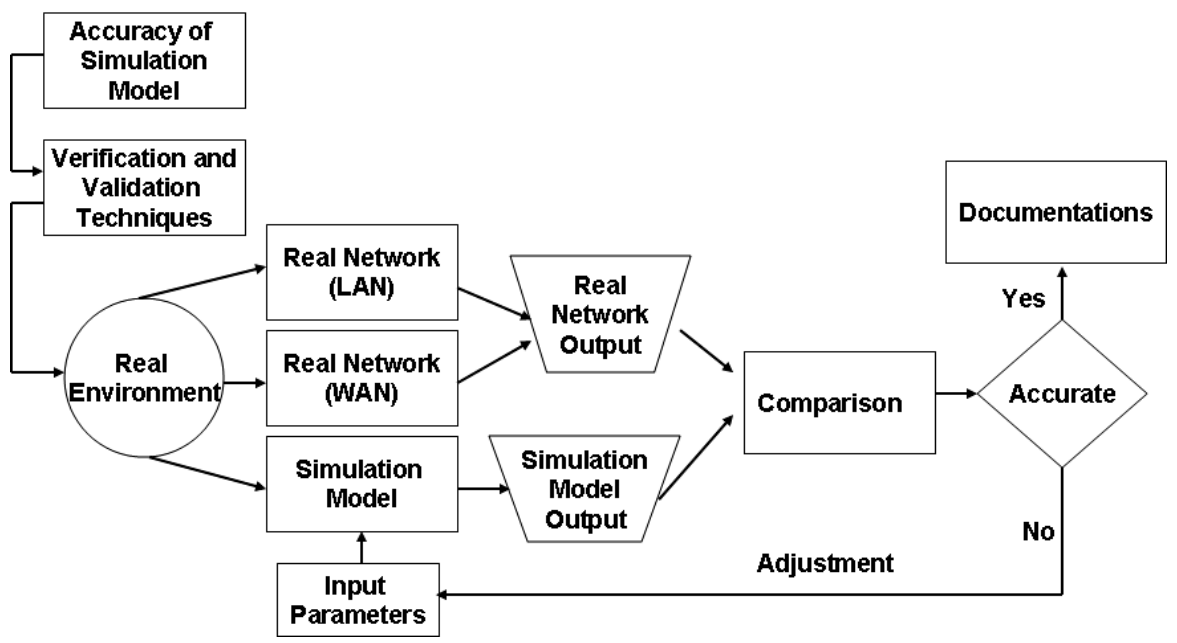

Figure 2. Simulation model verification and validation methodology.

clients receive services from the server. Simulation model is divided as follows: 1) to study physical of real heterogeneous network environment; 2) transform physical of real heterogeneous network environment into logical model; and 3) develop and implement the heterogeneous simulation model.

\subsection{Physical Model of Real Heterogeneous Network Environment}

Figure 3 shows the network heterogeneous environment in real world. Then, it needs to transform from heterogeneous environment in real world into logical model. The logical model is the phase where mathematical techniques are used to stimulate heterogeneous environment.

\subsection{Logical Model of Heterogeneous Network Environment}

Figure 4 depicts the open queuing network based on Queuing theory $(\mathrm{M} / \mathrm{M} / 1)$ will use to develop logical model of heterogeneous network environment for network traffic utilization. Queuing theory is robust enough to include many different combinations. Parameters like bandwidth capacity, size of packet services and number of clients are used to "characterize" the application traffic. 


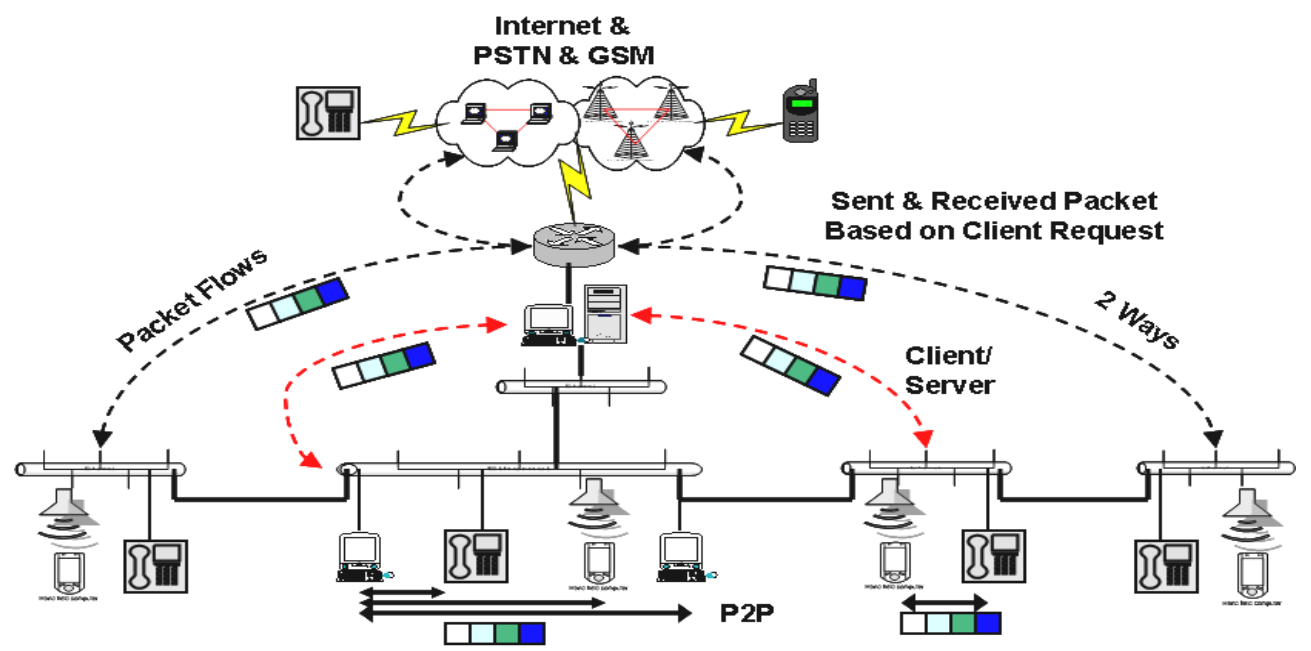

Legend:

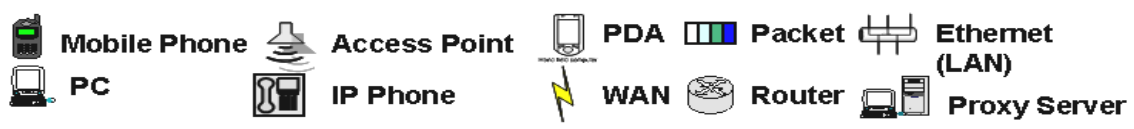

Figure 3. Real heterogeneous network environment at main and branch campus.

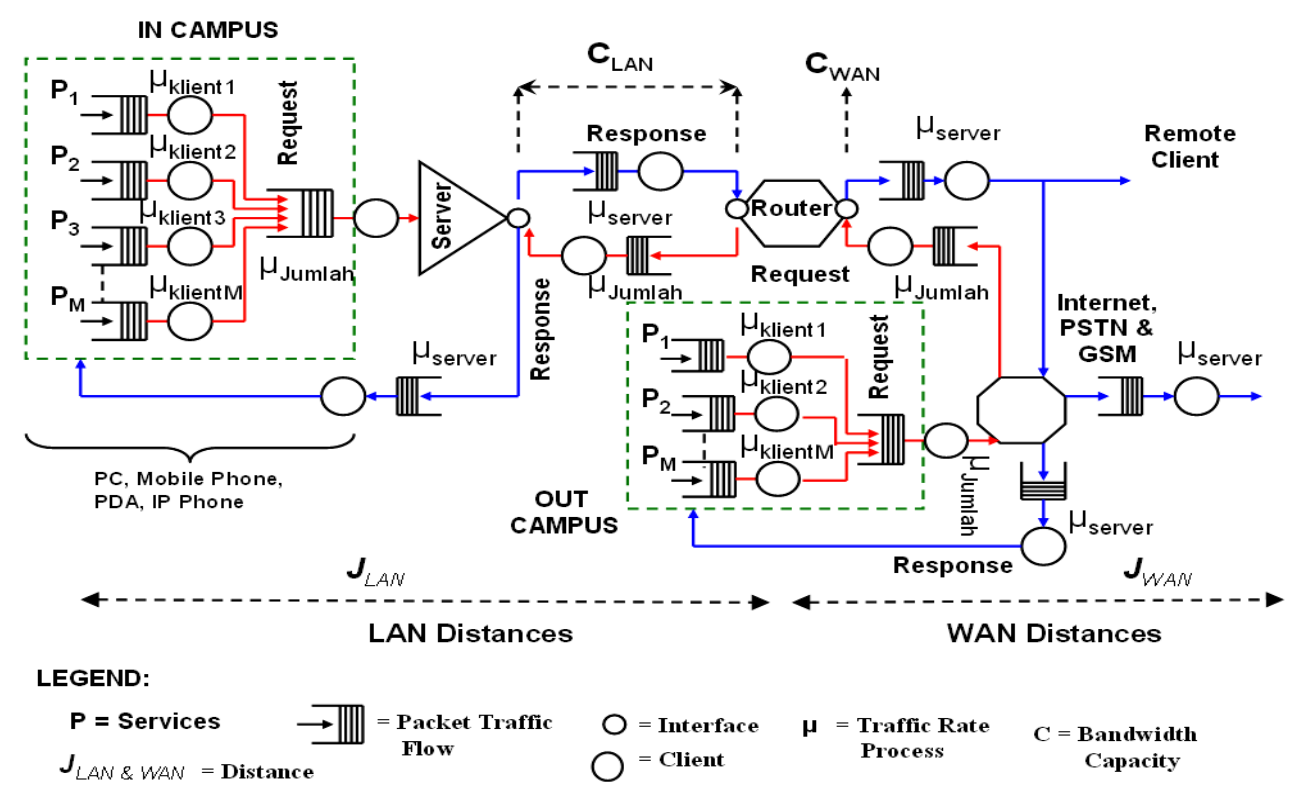

Figure 4. Logical model of heterogeneous environment at main and branch campus.

\subsection{Development of Heterogeneous Network Environment Model}

This section describes a simple analytical queuing and little law theories that capture the performance characteristics of network utilization and traffic operations. A link refers to a single connection between routers and hosts. The link bandwidth is the rate at which bits can be inserted into the medium. The faster bandwidth the more bits can be placed on the medium in a given time frame [25]. Table 1 shows the parameters that have been used in the model development. In open queuing network, the throughput of the heterogeneous network environment is determined by the input rate in the system. Table 2 summarizes all the parameters used in the model. 
The original Queuing theory is defined as an average number of clients in the system (variable name is " $N$ ") in Equation (1). Equation (2) is defined as traffic intensity use by clients in the system. Equation (1) and (2) are derived based on logical model that has been designed to meet requirements for heterogeneous network environment. Logical model is derived and formulated in a single service (homogeneous concept) as in Equations (3), (4), (5), (6) and (7). Then, the logical model is derived to the heterogeneous network environment in Equations (8), (9), (10), (11), (12), (13) and (14).

Figure 5 shows how the model has been formulated

$$
\mathrm{N}=\lambda * \mathrm{~T}
$$

$$
\rho=\frac{\lambda}{\mu}<1 ; \lambda<\mu
$$

from real network environment to simulation model. The main valuable aspects of the simulation study is to explain and understand real world phenomena that are costly to perform in the laboratory or difficult to collect in field experiments. A successful simulation model that is able to provide a sufficiently credible solution that can be used for prediction. Since it is not feasible to construct a simulation model that represents all the details and behaviors of the real network, some assumptions must be made about the real network to construct a simulation model. Therefore, a simulation model is an abstract representation of real network environment.

Table 1. Notations for original queuing and little theories.

\begin{tabular}{cl}
\hline Model Parameters & \multicolumn{1}{c}{ Meaning } \\
\hline $\mathrm{N}$ & Average number of clients in the system \\
$\mathrm{T}$ & Average time a client spends in the system (second) \\
$\lambda$ & Clients arrival rates \\
$\mu$ & Service rate in second \\
$1 / \mu$ & Mean service times \\
$\rho$ & Traffic intensity \\
\hline
\end{tabular}

Table 2. Notations for model development.

\begin{tabular}{cl}
\hline Model Parameters & \multicolumn{1}{c}{ Meaning } \\
\hline $\mathrm{N}$ & Average number of traffics on the network \\
$\mathrm{T}$ & Average time of clients arrive on the network (second) \\
$\mathrm{P}(\mathrm{P} 1, \mathrm{P} 2, \mathrm{P} 3, \ldots \mathrm{Pm})$ & Various of services \\
$\mathrm{P} 1$ & Client uses single service \\
$\mu_{\mathrm{klient}}$ & Size of packet service request by client ( traffic) \\
$\mu_{\text {server }}$ & Traffic response from server to clients \\
$\mathrm{N}_{\mathrm{klient}+\text { server }}$ & Number of clients in second over single service \\
$\mathrm{U}_{\text {klient }+ \text { server }}$ & Network traffic utilization usage based on number of clients in second over single \\
$\mathrm{C}\left(\mathrm{C}_{\mathrm{LAN},} \mathrm{C}_{\mathrm{WAN}}\right)$ & Size of Bandwidth on LAN and WAN interface ports \\
$\mathrm{U}_{\text {hetergenes }}$ & Network traffic utilization usage for heterogeneous environment \\
$\mathrm{Heter}_{\text {klient }+ \text { server }}$ & Number of clients and traffics over heterogeneous environment \\
$\mu_{\text {Jumlah }}$ & Total size of packet services request by clients (traffic) \\
Jum_klient $_{-}$ & Number of clients \\
$\mathrm{T}_{\mathrm{jum}}$ & Total number of clients access on the network in second \\
\hline
\end{tabular}

Client uses single service for accessing network server

$$
\begin{aligned}
& \mathrm{N}=\boldsymbol{\mu}_{\text {klient }} *\left(\mathrm{Jum}_{\text {_ }} \text { klient } * \mathrm{~T}\right) \\
& \mathrm{N}_{\text {klient }}+\text { server }=\mathrm{P}_{1} *\left(\mathrm{Jum} \_ \text {klient } * \mathrm{~T}\right) \\
& \mathrm{N}_{\mathrm{klient}+\text { server }}=(\text { Minta }+ \text { Balas }) *(\text { Jum_klient } * \mathrm{~T}) \\
& \text { Nklient }+ \text { server }=\left(\mu_{\text {klient }}+\mu_{\text {server }}\right) \cdot\left(J_{u m} \text { klient } * \mathrm{~T}\right)
\end{aligned}
$$




$$
\mathrm{U}_{\text {klient }}+\text { server }=\mathrm{N}_{\text {klient }}+\text { server } / \mathrm{C}
$$

Client uses various services for accessing network server in Heterogeneous Environment

$$
\begin{aligned}
& \mathrm{T}_{\mathrm{Jum}}=\text { Jum_klient } * \mathrm{~T} \\
& \text { Heter klient }+ \text { server }=\left(\mathrm{P}_{1}+\mathrm{P}_{2}+\mathrm{P}_{3}+\ldots .+\mathrm{Pm}_{\mathrm{m}}\right) * \mathrm{~T} \text { Jum } \\
& \text { Heterklient }+ \text { server }=\left[\left(\mu_{\text {klient } 1}+\mu_{\text {klient } 2}+\mu_{\text {klient } 3}+\ldots+\mu_{\text {klient } \_m}\right)+\mu_{\text {server }}\right] * \text { TJum } \\
& \text { Heter klient }+ \text { server }=\left[\left(\mu_{\text {Jumlah }}\right)+\left(\mu_{\text {server }}\right)\right] * \text { T Jum } \\
& \text { Heter klient }+ \text { server }=\left[\left(\mu_{\text {Jumlah }}\right)+\left(\mu_{\text {server }}\right)\right] * \text { T Jum } \\
& \text { where } \mathrm{P}_{1}+\mathrm{P}_{2}+\mathrm{P}_{3}+\ldots+\mathrm{Pm}=\mathrm{U}_{\text {klient } 1}+\mathrm{U}_{\text {klient } 2}+\mathrm{U}_{\text {klient } 3}+\ldots+\mathrm{U}_{\text {klientm }}=\mu_{\text {jumlah }} \\
& \mathrm{U}_{\text {hetergenes }}=\text { Heter }_{\text {klient }}+\text { server } / \mathrm{C}
\end{aligned}
$$

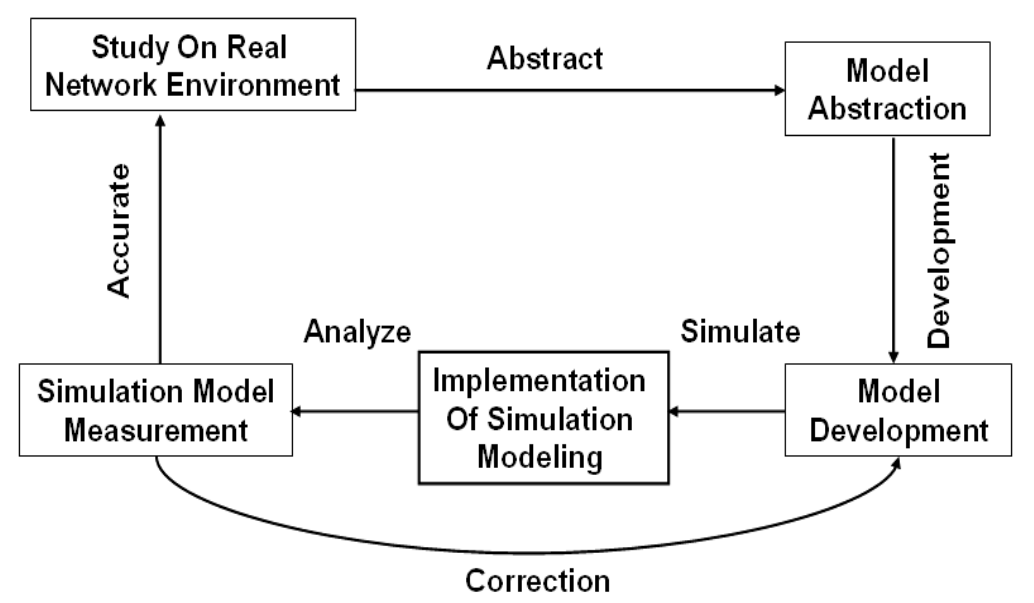

Figure 5. Model and simulation development phases.

\section{Verification and Validation of Simulation Model with Real Network Experimental}

Lab experiment is based on ideal network in which there is no packet losses, no jitter in delays and network bandwidth is sufficient for all requirements. While, real experiment is based on real network and need to consider as follows: 1) network bandwidth is limited and is not enough for all application and users at the same time; 2) delay due to the network overloads; and 3) packet losses.

\subsection{Real Network Setup}

This research used a network management application to capture traffic between two networks link in real network environment. Figure 6 shows the experimental setup of real network used in our tests. The real network used switch with Gigabit Ethernet ports, Router ports and Fluke Optiview device can be configured to insert size of packet services and number of clients to generate traffic into the network interface (see Figure 7). By using varying number of clients and size of packet services, Fluke Optiview device is able to simulate network utilization and traffic.

\subsection{Real Network Experiment}

This research has setup a real network environment of network utilization measurement that generates measurement data to analyze network performance at the main campus. The real network is based on local area network (LAN). The traffics will pump into LAN 100 Mbps (real network) to access network server (see Figure 7). Low bandwidth link affects the size of packet services and number of clients' access to the network server. Therefore, network management application is used to measure traffic and its network utilization performance (see Figure 8). Five sets of experiments were conducted with different scenarios (see Table 3 and 
Table 4). Fluke Optiview device is able to generate maximum traffic to 1518 bytes (12144 bits) only in the real network (see Figure 7 and Figure 10). The same input variables have been used in simulation model (see Figure 9 and Table 4) to estimate our data that must be closely resemble to real network environment (see Table 5). This research is concluded that base on our findings, the simulation model is able to predict and estimate network utilization usage for real network environment (see Table 3 and Table 4).

\subsection{Comparison of Real Network, Simulation Model and Relative Error Rates}

Figure 11 shows a comparison between simulation model, real network and relative error rate using LAN $100 \mathrm{Mbps}$. The result shows both scenarios use in simulation model and real network are able to predict and measure network traffic utilization. The simulation model provides relatively accurate results when compared to the real network over LAN 100 Mbps. Figure 11 also shows the

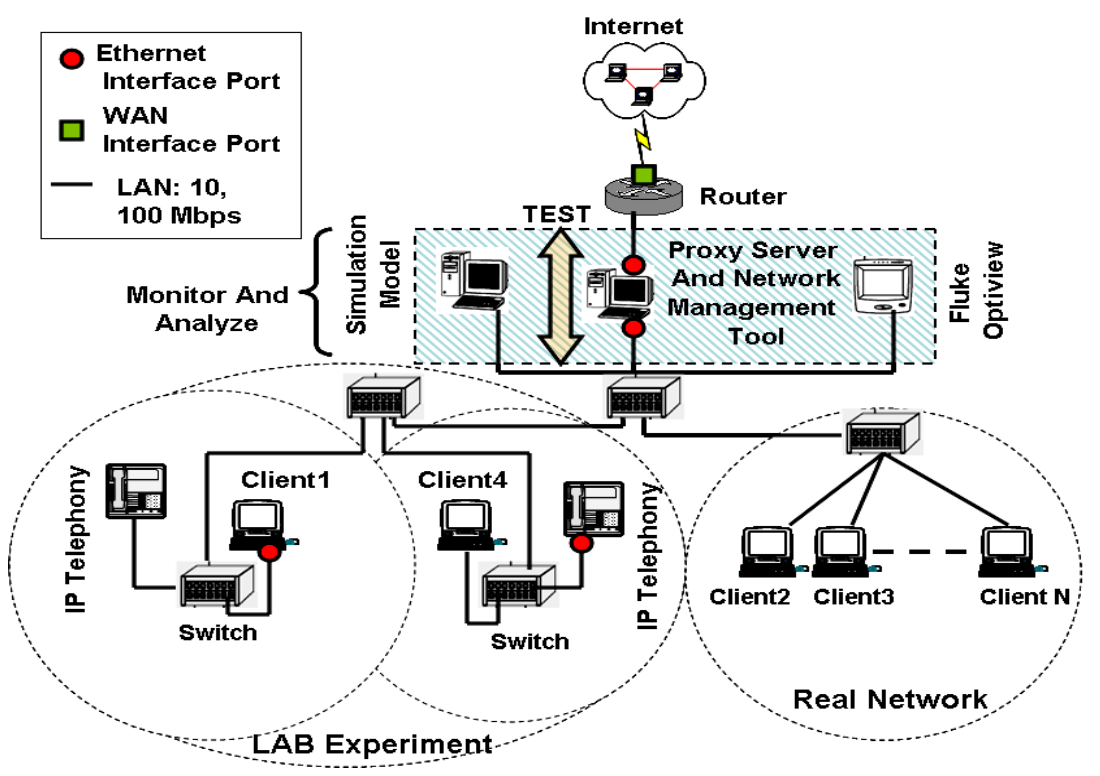

Figure 6. Experimental laboratory for real network environment setup.

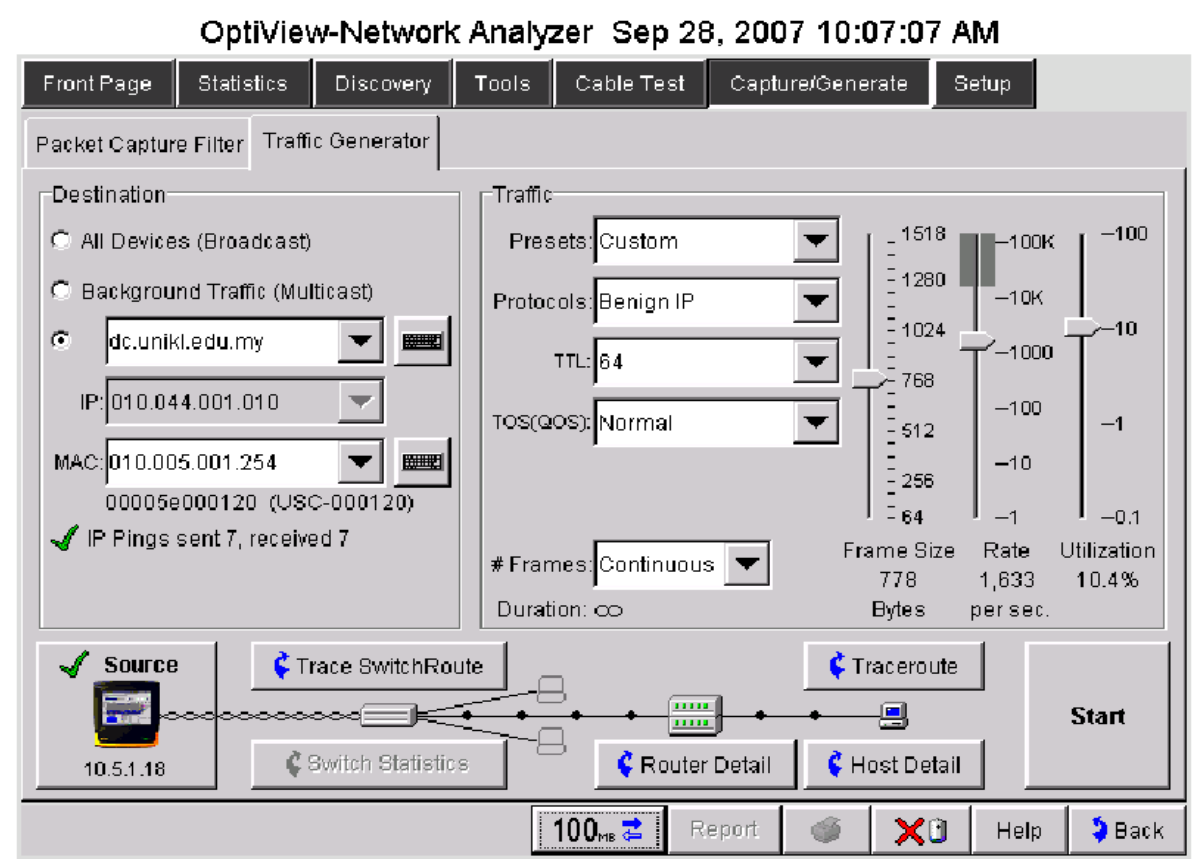

Figure 7. Fluke Optiview engine setting for size of packet services and clients. 


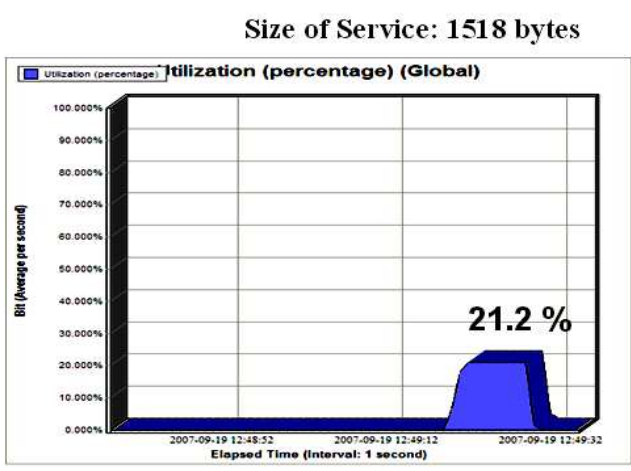

Size of Service: 831 bytes

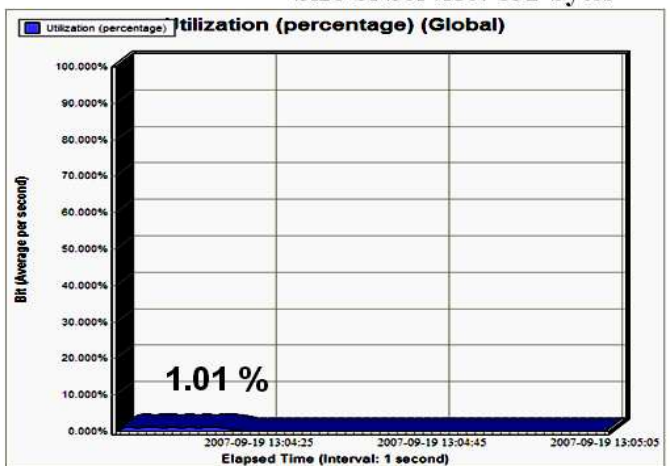

Number of Clients: 1726

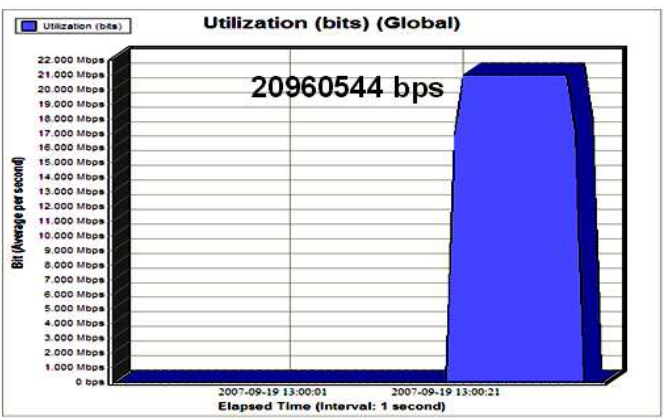

Number of Clients: 149

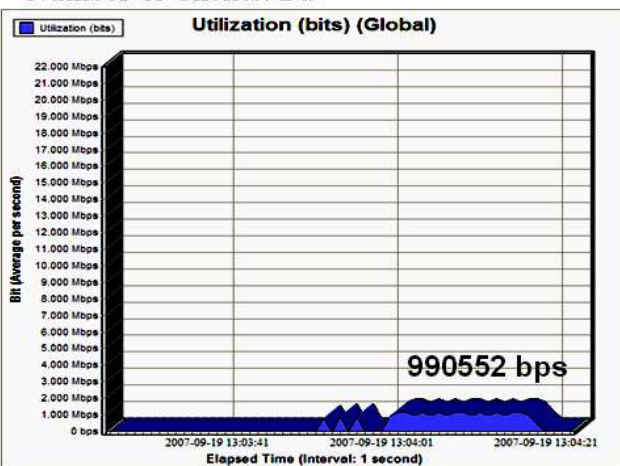

Figure 8. Real network experiment result capture by network management application (100 mbps).

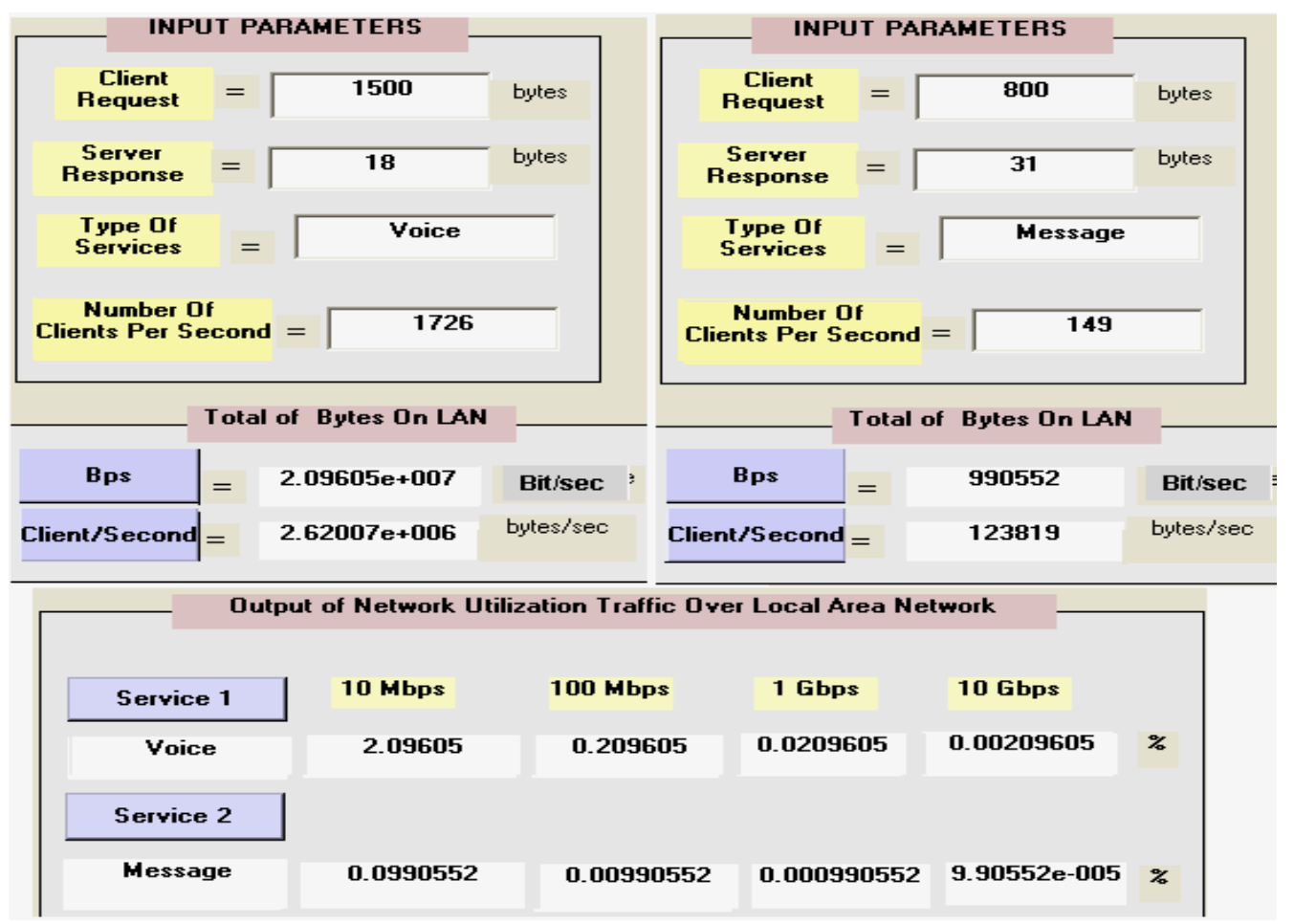

Figure 9. Prediction of network traffic utilization over 100 mbps via simulation model.

comparison of relative error rates between simulation model and real network environment. As a result, this research shows that the simulation model can predict real network experiments with minimum relative error rates. Therefore, from the prediction and estimation result, this simulation model can assist network administrator 
Optiview-Network Analyzer Oct 2, 2007 12:41:38 PM

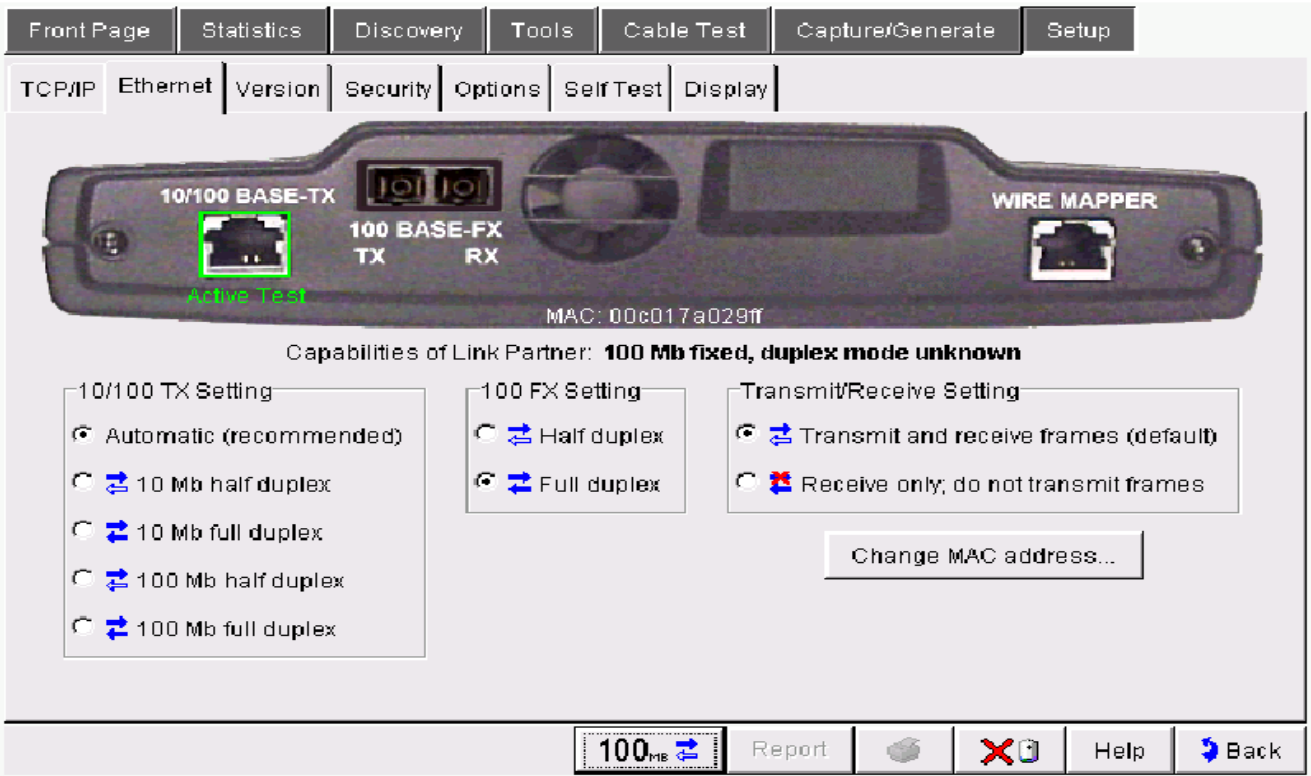

Figure 10. Fluke Optiview device architecture.

Table 3. Network traffic utilization over 100 mbps for real network experiments.

\begin{tabular}{|c|c|c|c|c|c|}
\hline $\begin{array}{c}\text { Frame Size } \\
\text { (Bytes) }\end{array}$ & $\begin{array}{c}\text { Number of } \\
\text { Clients } \\
\text { (second) }\end{array}$ & $\begin{array}{c}\text { Traffic in } \\
\text { Bytes/Second }\end{array}$ & $\begin{array}{c}\text { Traffic in } \\
\text { Bit/Second }\end{array}$ & $\begin{array}{c}\text { Utilization (1- } \\
\mathbf{1 0 0 \% )}\end{array}$ & $\begin{array}{c}\text { Utilization } \\
\mathbf{( 0 . 1 - 1 \% )}\end{array}$ \\
\hline 512 & 262 & 134144 & 1073152 & 1.11 & 0.0111 \\
\hline 778 & 1633 & 1270474 & 10163792 & 10.4 & 0.104 \\
\hline 831 & 149 & 123819 & 990552 & 1.01 & 0.0101 \\
\hline 1042 & 3961 & 4127362 & 33018896 & 33.7 & 0.337 \\
\hline 1518 & 1726 & 2620068 & 20960544 & 21.2 & 0.212 \\
\hline
\end{tabular}

Table 4. Network Traffic utilization over 100 mbps using simulation model.

\begin{tabular}{|c|c|c|c|c|c|}
\hline $\begin{array}{c}\text { Frame Size (Client }+ \\
\text { Server); (Bytes) }\end{array}$ & $\begin{array}{c}\text { Number of } \\
\text { Clients } \\
\text { (second) }\end{array}$ & $\begin{array}{c}\text { Traffic in } \\
\text { Bytes/Second }\end{array}$ & $\begin{array}{c}\text { Traffic in } \\
\text { Bit/Second }\end{array}$ & $\begin{array}{c}\text { Utilization } \\
(\mathbf{1 - 1 0 0 \% )}\end{array}$ & $\begin{array}{c}\text { Utilization } \\
\mathbf{( 0 . 1 - 1 \% )}\end{array}$ \\
\hline 512 & 262 & 134144 & 1073152 & 1.07 & 0.01073152 \\
\hline 778 & 1633 & 1270474 & 10163792 & 10.1638 & 0.101638 \\
\hline 831 & 149 & 123819 & 990552 & 0.99 & 0.0099 \\
\hline 1042 & 3961 & 4127362 & 33018896 & 33.01 & 0.3301 \\
\hline 1518 & 1726 & 2620068 & 20960544 & 20.96 & 0.2096 \\
\hline
\end{tabular}

Table 5. Comparison of relative error rates between simulation model and real network environment.

\begin{tabular}{|c|c|c|c|c|}
\hline $\begin{array}{c}\text { Frame Size (Client }+ \\
\text { Server); (Bytes) }\end{array}$ & $\begin{array}{c}\text { Number of } \\
\text { Clients } \\
\text { (second) }\end{array}$ & $\begin{array}{c}\text { Utilization } \\
\text { (Simulation Model) } \\
(\mathbf{0 . 1 - 1 \% )}\end{array}$ & $\begin{array}{c}\text { Utilization } \\
\text { (Real Network) } \\
\mathbf{( 0 . 1 - 1 \% )}\end{array}$ & $\begin{array}{c}\text { Relative Error } \\
\text { Rates }\end{array}$ \\
\hline 778 & 812 & 0.01073152 & 0.0111 & 0.000119 \\
\hline 831 & 393 & 0.101638 & 0.104 & 0.002362 \\
\hline 1033 & 393 & 0.0099 & 0.0101 & 0.0002 \\
\hline 1518 & 180 & 0.3301 & 0.337 & 0.0069 \\
\hline
\end{tabular}

to plan, propose and design network topology more systematic and efficiently for heterogeneous network environment.

\section{Conclusions and Future Work}

This article has shown how an analytical queuing model 


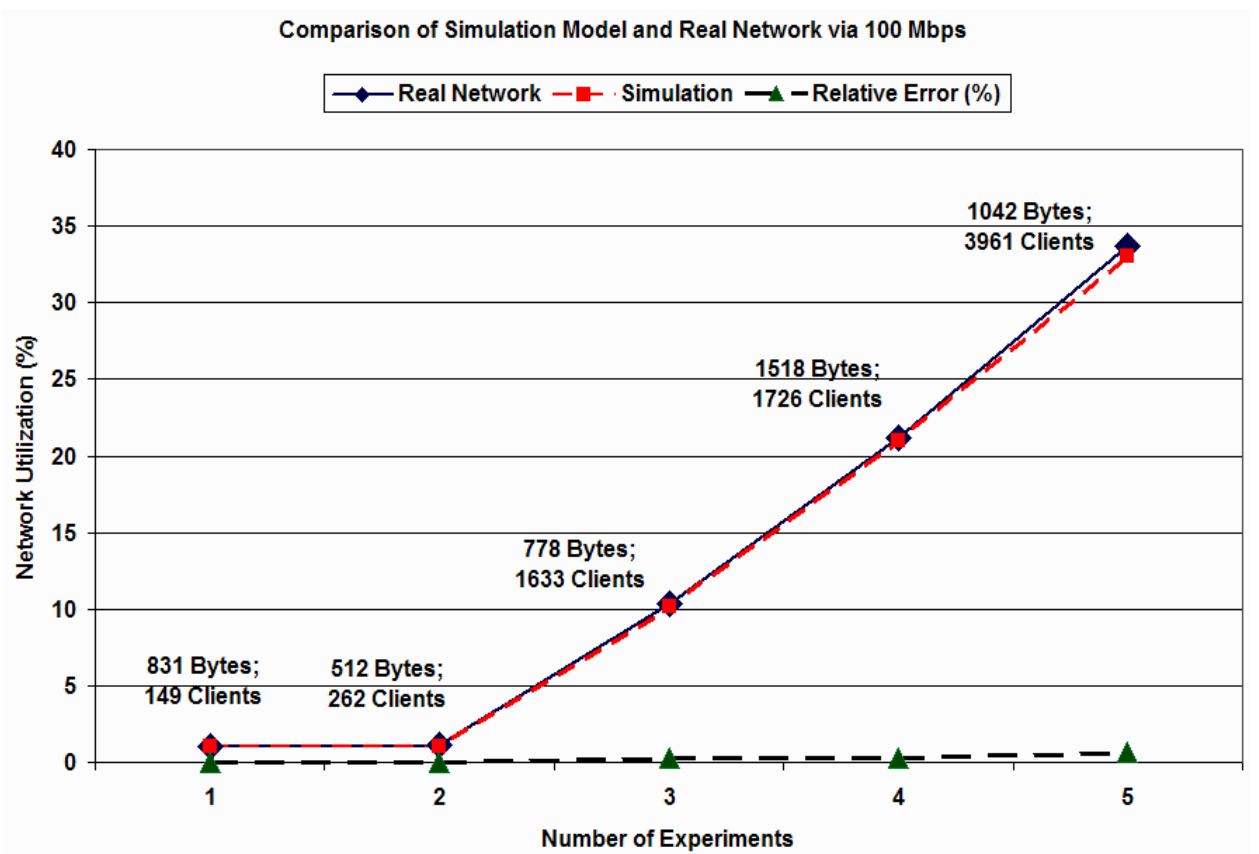

Figure 11. Comparison of simulation model with real network using $100 \mathrm{mbps}$ variable and relative error rate.

can be used to understand the behaviors of heterogeneous environment over LAN experiments. The most apparent aspect is the utilization usage due to size of bandwidth and number of clients. Our simulation model, has demonstrated that it can measure accurately the performance of heterogeneous services and technologies to access network server. Through real network experiments, the simulation model is verified and validated for providing accurate performance information for various services. The simulation-modeling framework described in this study can be used to study other variations, tunings, and similar new ideas for various services and technologies. Network utilization rate will directly affect the network performance. In network management, by monitoring and analyzing network utilization rate, network administrator can monitor the performance of the network, thus to study whether network is normal, optimal or overloaded. Network utilization rate also plays an important role in benchmark setting and network troubleshooting. Future work is to develop a simulation model to analyze bandwidth capacity requirement for various services and technologies in heterogeneous environment.

\section{References}

[1] S. Kawasaki, Niwa, et al., "A study on formulation of the ubiquitous cloud model", Mobile Data Management, 2006, MDM 2006, 7th International Conference, pp. 148148, 2006.

[2] A. Tsalgatidou, G. Athanasopoulos, et al., "Developing scientific workflows from heterogeneous services," ACM SIGMOD, Vol. 35 (2), pp. 22-28, 2006.
[3] Q. W. Liu, S. L. Zhou, et al., "Cross-layer modeling of adaptive wireless links for QoS support in heterogeneous wired-wireless networks," Wireless Networks, Vol. 12 (4), Kluwer Academic Publishers, 2006.

[4] R. Puigjaner, "Performance modelling of computer networks," IFIP/ACM Latin America Networking Conference 2003, La Paz, Bolivia. ACM 2003, October 3-5, 2003.

[5] S. Fredj, T. Bonald, A. Proutiere, G. Regnie, and J. Roberts. "Statistical bandwidth sharing: A study of congestion at flow level," in Proceedings of ACM SIGCOMM '01, San Diego, CA, August 2001.

[6] G. J. Jin and B. L. Tierney, "System capability effects on algorithms for network bandwidth measurement," Proceedings of the 3rd ACM SIGCOMM conference on Internet measurement, pp. 27-38, 2003.

[7] J. Cong and B. E. Wolfinger, "A unified load generator based on formal load specification and load transformation," Proceedings of the 1st international conference on Performance evaluation methodologies and tools, ACM International Conference Proceeding Series, Pisa, Italy, Vol. 180 (53), 2006.

[8] S. B. Fredj, T. Bonald, and A. Proutiere, G. Regnie and J. Roberts, "Statistical bandwidth sharing: A study of congestion at flow level," ACM SIGCOMM, August 2001.

[9] T. Bu and D. Towsley, "Fixed point approximation for TCP behavior in an AQM network", ACM SIGMETRICS, June 2001.

[10] A. A. Kherani and A. Kumar, "Performance analysis of TCP with nonpersistent sessions", Workshop on Modeling of Flow and Congestion Control, INRIA, Ecole Normale Superieure, Paris, September 4-6, 2000.

[11] Q. G. Zhao, X. M. Fang, Q. Z. Li, and Z. Y. He, "WNNbased NGN traffic prediction," ISADS 2005, Proceedings 
Autonomous Decentralized Systems, pp. 230-234, 2005.

[12] C. Barakat, P. Thiran, G. Iannaccone, C. Diot, and P. Owezarski. "Modeling Internet backbone traffic at the flow level". IEEE Transactions on Signal Processings (Special Issue on Networking), August 2003.

[13] T. Bu and D. Towsley, "Fixed point approximation for TCP behavior in an AQM network," in Proceedings of ACM SIGMETRICS '01, San Diego, CA, June 2001.

[14] P. Podhradsky, "Migration scenarios and convergence processes towards NGN (present state and future trends)," Electronics in Marine Proceedings Elmar. 46th International Symposium, pp. 39-46, 2004.

[15] G. Nogueira, "Measurement based validation of GPRS/ EDGE analytical models".

[16] J. Heidemann, K. Mills, and S. Kumar, "Expanding confidence in network simulation," IEEE computer, Vol. 15 (5), pp. 58-63, 2001.

[17] C. Barakat, P. Thiran, G. Iannaccone, C. Diot, and P. Owezarski, "A flow-based model for Internet backbone traffic," Proceedings of the 2nd ACM SIGCOMM Workshop on Internet measurement, Marseille, France, pp. 35-47, 2002.

[18] J. kontio and R. Conradi, "Evaluating the performance of a web site via queuing theory," Software Quality - ECSQ 2002: 7th International Conference, Helsinki, Finland, pp. 63-72, Springer-Verlag Berlin Heideberg, June 9-13, 2002.
[19] K. H. Lee, K. O. Lee, K. C. Park, J. O. Lee, and Y. H. Bang, "Architecture to be deployed on strategies of nextgeneration networks," Communications ICC '03, The IEEE, Vol. 2, pp. 819-822, 2003.

[20] J. Q. Li, Z. H. Sun, 2004, "Internet/Web technology in higher education in China," Advanced Learning Technologies, Proceedings IEEE International Conference, pp. 993-997, 2004.

[21] X. X. Jiang, F. C. Yang, and H. Zou, "A novel architecture to customer service management for the NGN," ICCT 2003. International Conference, 1: 123-126, 2003.

[22] B. Thai, R. Wan, A. Seneviratne, and T. Rakotoarivelo, "Integrated personal mobility architecture: A complete personal mobility solution," Kluwer Academic Publishers, 2003.

[23] J. Curtis and T. McGregor, "Review of bandwidth estimation techniques," in Proceedings New Zealand Computer Science Research Students' Conference, Vol. 8, New Zealand, April 2001.

[24] D. R. Gerhan and S. M. Mutula, "Bandwidth bottlenecks at the University of Botswana," Published by Emerald Group, Vol. 23 (1), pp. 102-117, 2005.

[25] J. Sommers and P. Barford, "Self-configuring network traffic generation," in Proceedings of ACM Internet Measurement Conference, October 2004. 